\title{
Trans-cranial focused ultrasound without hair shaving: feasibility study in an ex vivo cadaver model
}

\author{
Matthew DC Eames', Arik Hananel ${ }^{1,2^{*}}$, John W Snell ${ }^{1,3}$, Neal F Kassell ${ }^{1,3}$ and Jean-Francois Aubry ${ }^{2,4}$
}

\begin{abstract}
In preparing a patient for a trans-cranial magnetic resonance (MR)-guided focused ultrasound procedure, current practice is to shave the patient's head on treatment day. Here we present an initial attempt to evaluate the feasibility of trans-cranial focused ultrasound in an unshaved, ex vivo human head model. A human skull filled with tissue-mimicking phantom and covered with a wig made of human hair was sonicated using 220- and $710-\mathrm{kHz}$ head transducers to evaluate the feasibility of acoustic energy transfer. Heating at the focal point was measured by MR proton resonance shift thermometry. Results showed that the hair had a negligible effect on focal spot thermal rise at $220 \mathrm{kHz}$ and a 17\% drop in temperature elevation when using $710 \mathrm{kHz}$.
\end{abstract}

Keywords: tcMRgFUS, Brain, Hair, MR thermometry

\section{Introduction}

Focused ultrasound (FUS), or high-intensity focused ultrasound (HIFU), involves depositing ultrasonic energy into a target volume, where the area of acoustic emission is significantly greater than the focal area. This focusing effect allows generation of a high level of acoustic intensity at the target volume, thereby triggering and amplifying a variety of bio-effects ranging from thermal to mechanical. Currently, the most common usage of HIFU in clinical practice is for noninvasive thermal ablation with close to 100,000 patients treated worldwide, mainly for the indications of prostate cancer $[1,2]$, liver cancer [3-5], breast cancer [6,7], and symptomatic uterine fibroids [8-10].

Treatments are performed under image guidance, either by magnetic resonance imaging (MRI; MRgFUS, MR-guided FUS) [11,12] or by ultrasonic imaging (USgFUS, US-guided FUS) $[13,14]$.

HIFU, being a noninvasive, accurate, radiation-free thermal ablation tool, has long been viewed as an ideal treatment tool for various brain indications [15-17].

\footnotetext{
* Correspondence: ahananel@fusfoundation.org

${ }^{1}$ Focused Ultrasound Foundation, Charlottesville, VA 22903, USA

2Department of Radiation Oncology, University of Virginia, Charlottesville, VA 22908, USA

Full list of author information is available at the end of the article
}

However, the usage of HIFU for the brain is hampered by the defocusing of the ultrasonic beam by the patient skull $[18,19]$. The development of aberration correction techniques [20-22] has led to a significant increase in clinical research involving trans-cranial MRgFUS (tcMRgFUS), mainly as a functional neurosurgery tool for treatment of essential tremor [23] and neuropathic pain [24] with more than 80 patients treated worldwide to date.

Current practice requires shaving the patient's head on tcMRgFUS treatment day. This practice, although noninvasive and scientifically and clinically sound, is often a concern to patients. In addition, it presents a potential limitation if and when there will be a need for a repeated tcMRgFUS in the cases of BBB opening [25-27] that should be synced to chemotherapy administration or when 'time to treat' may be limited, as could be the case in stroke clot lysis [28,29]. Earlier work by Raymond and Hynynen [30] has shown in a lab model that insertion loss due to strands of hair aligned perpendicular to beam propagation is frequency dependent and that it is less than $20 \%$ for frequencies less than $1.7 \mathrm{MHz}$.

Here we present an initial attempt to evaluate the feasibility of tcMRgFUS in a close to full clinical model using an ex vivo cadaver skull with and without a wig made of human hair.

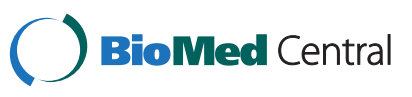




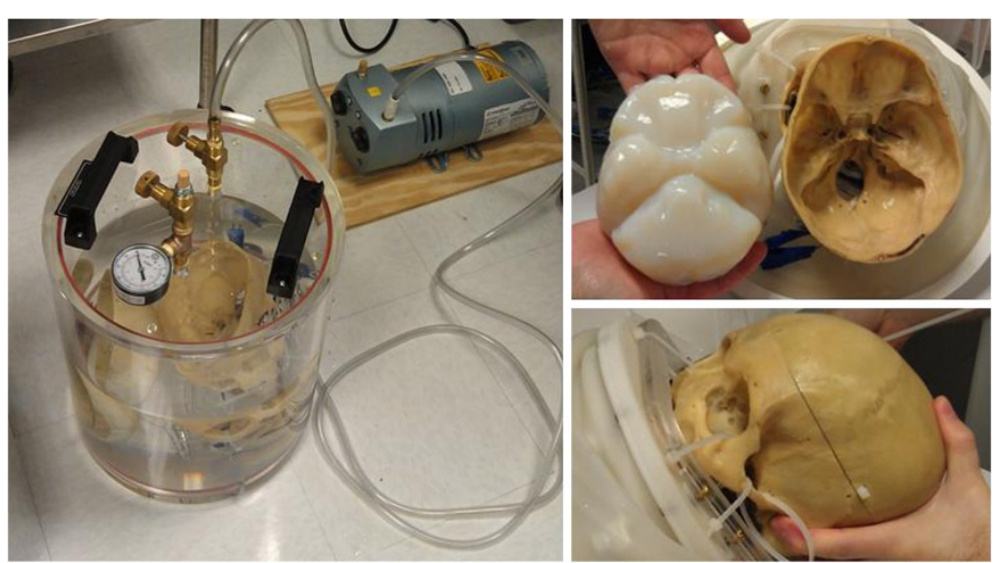

Figure 1 Degassing of the cadaver skull, filling with tissue-mimicking phantom, and setting for placement inside the ExAblate-Neuro.

\section{Methods}

A human cadaveric skull was recovered from a cadaver obtained through the Virginia Department of Health State Anatomical Program. The skull was defleshed and cleaned and then stored for 12 months in air at room temperature before starting the current experiment. To build a model as close as possible to a patient's head, in terms of size and acoustic properties, the skull was filled with tissue-mimicking hydrogel (ATS Laboratories, Bridgeport, CT, USA) (Figure 1). Acoustic properties of the gel provided by the manufacturer were as follows: speed of sound $(1,540 \mathrm{~m} / \mathrm{s})$, absorption coefficient $(0.5 \mathrm{~dB} / \mathrm{cm} / \mathrm{MHz})$. The hydrogel was melted in an $800-\mathrm{W}$ microwave (Oster model OM0701A8B, Foshan, Guangdong, China) at 50\% power for $12 \mathrm{~min}$. The temperature of the hydrogel right after melting in the microwave was $51^{\circ} \mathrm{C}$. The inside of the upper and lower halves of the skull were lined with plastic film to create a watertight mold into which the gel was poured and cooled to approximately $5^{\circ} \mathrm{C}$ for at least $8 \mathrm{~h}$ to solidify.
The human ex vivo skull was degassed in water with less than $2 \mathrm{ppm}$ oxygen for $20 \mathrm{~min}$ in a vacuum chamber (Acrylic Round Vacuum Chamber, Abbess, Holliston, MA, USA) at $230 \mathrm{mmHg}$. Once degassed, the upper and lower gel molds were placed inside the upper and lower parts of the skull while still submerged in water. The two halves of the skull were connected together while submerged in water. For the cases in which a wig was used, it was submerged in the degassed water, gently stirred to remove trapped air bubbles and then placed on the skull. The skull assembly was then mounted in the ExAblateNeuro (InSightec, Tirat Hakarmel, Israel) ultrasound transducer, which was promptly filled with water to minimize the presence of air in the experimental setup. This process was repeated with two ExAblate-Neuro transducers, each with a different operating frequency (220 and $710 \mathrm{kHz}$ ).

The hair is attached to the wig by the manufacturer with a dedicated cap. In order to investigate the relative influence of the hair and the cap, three setups were tested for each transducer: the bare skull (Figure 2),
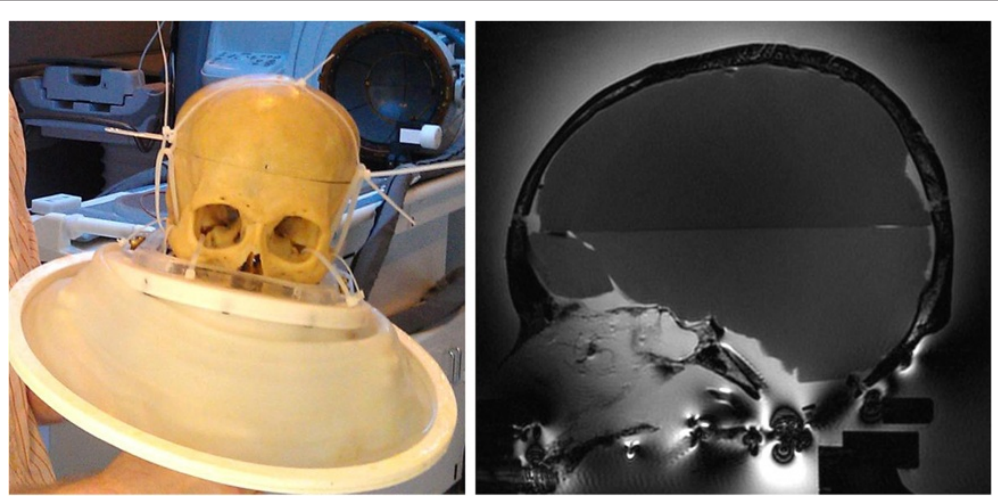

Figure 2 Bare skull strapped to holder (left) and as seen on MR T2w sagittal image (right). 

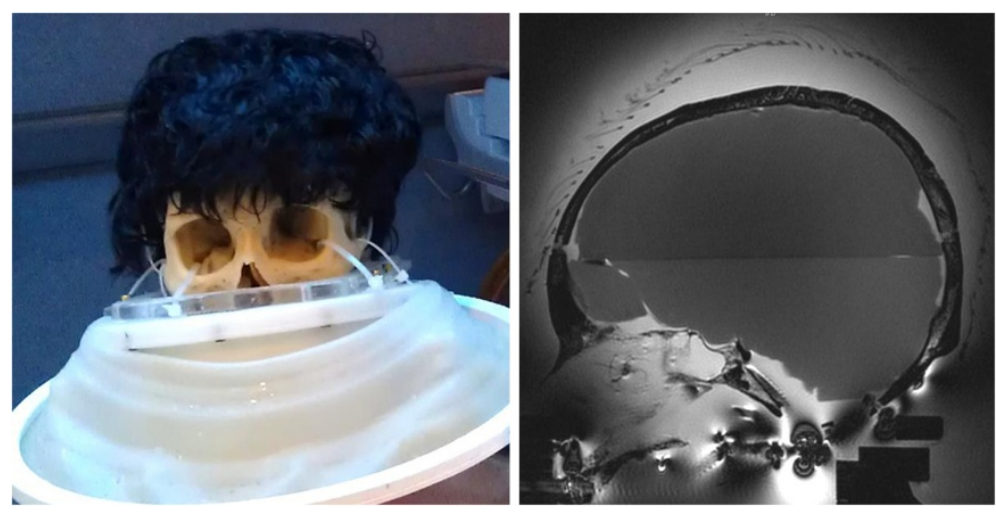

Figure 3 Skull with wig strapped to holder (left) and as seen on MR T2w sagittal image (right).

the same skull covered with a human hair wig $(\mathrm{H}-222$, color 1, by Vivica Fox, Vivica A. Fox Hair Collection, Conshohocken, PA, USA; Figure 3), and the skull covered with only the cap part of the wig (used as baseline for the wig setup; Figure 4) after cutting the hair.

For each of the above setups, multiple 10-s-duration sonications were performed with increasing power. Power range varied between 120 and $420 \mathrm{~W}(120,180$, $240,300,360$, and $420 \mathrm{~W}$ ) with 10-s duration and duty cycle of $100 \%$.

During energy deposition, gel thermal rise in the focal point and near the skull was evaluated using the proton resonance frequency (PRF) shift method of MR temperature mapping. The MR system was a 3T discovery (GE, Milwaukee, WI, USA). The MR thermometry scan parameters used were as follows: TR/TE $27.6 / 12.8 \mathrm{~ms}$, flip angle $30^{\circ}$, bandwidth $5.68 \mathrm{kHz}$, FOV $28 \mathrm{~cm}$, slice thickness $3 \mathrm{~mm}$, matrix $256 \times 128$, scan time $3 \mathrm{~s}$. A temperature sensitivity of $-0.009 \mathrm{ppm} /{ }^{\circ} \mathrm{C}$ was used [31]. Three independent measurements were performed for each power and each configuration. Thermal rise at the focus as a function of power was fitted with a constrained linear least squares method (MATLAB, MathWorks, Natick, MA, USA).

\section{Results}

Temperature elevation is plotted as a function of energy in Figure 5 for the 220- (left) and $710-\mathrm{kHz}$ (right) setups for each configuration: the entire wig (wig and cap), the cap only, and the skull alone (no wig and no cap). Results of the corresponding constrained linear least squares fit are summarized in Table 1.

Temperature elevation with and without the wig showed a $19 \%$ decrease at $220 \mathrm{kHz}$ and $53 \%$ at $710 \mathrm{kHz}$. One can notice that most of the attenuation is in fact linked to the presence of the cap: there is no noticeable difference in temperature rise between the cap and the cap-and-wig setup at $220 \mathrm{kHz}$, and there is a limited $17 \%$ reduction at $710 \mathrm{kHz}$. The frequency-dependent impact on acoustic transmission can be better visualized by comparing the hair to cap ratio in both frequencies (Figure 6).

\section{Discussion}

The results show that the hair induces a minimal additional loss compared to the skull itself. The effect of the hair alone, after taking into account the effect of the cap, corresponds to a $17 \%$ decrease in temperature elevation at the focus at $710 \mathrm{kHz}$ and no noticeable

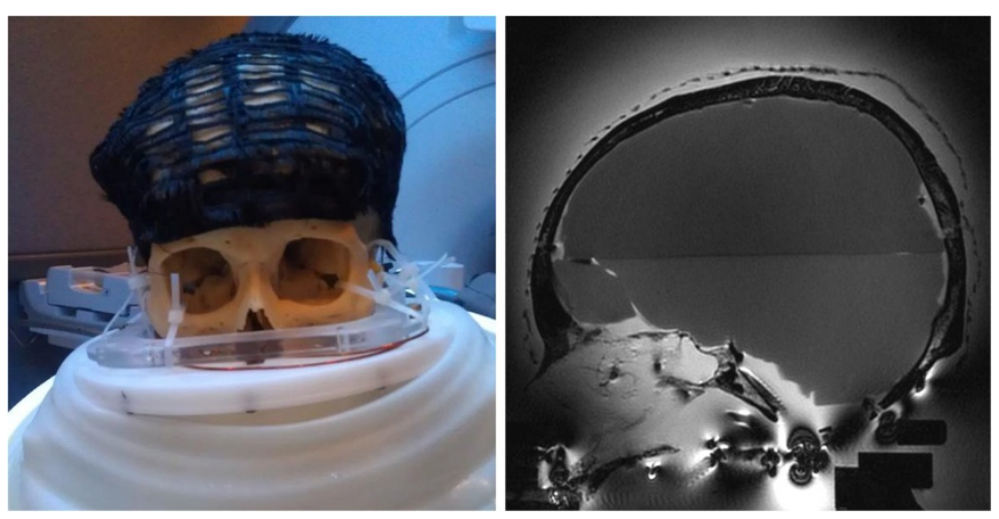

Figure 4 Skull with wig cap strapped to holder (left) and as seen on MR T2w sagittal image (right). 

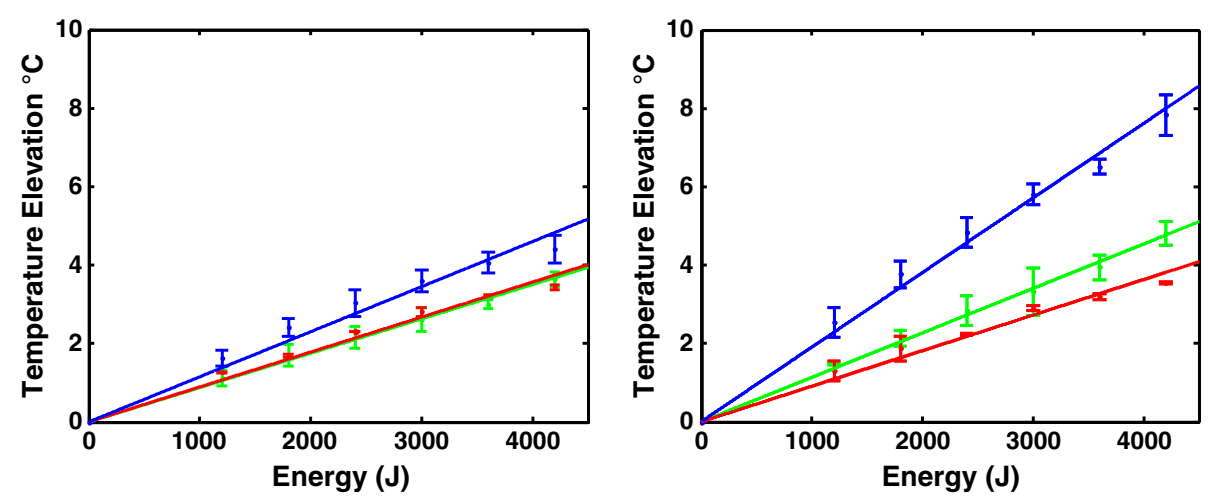

Figure 5 Temperature elevation as a function of energy. Measured heating using $220 \mathrm{kHz}$ (left) and $710 \mathrm{kHz}$ (right) in bare (blue), cap (green), and wig (red) skull setups. Standard deviation is displayed as error bars.

change at $220 \mathrm{kHz}$. Temperature elevation at the focus, being proportional to the square of the focal pressure, corresponds to a $4 \%$ decrease in the pressure at $710 \mathrm{kHz}$ and no significant decrease at $220 \mathrm{kHz}$. These numbers need to be discussed in the light of the energy loss associated with the errors induced by imperfect phase aberration correction. Current noninvasive aberration correction techniques are not perfect, and this leads to a significant drop in the final focal temperature rise as compared to the best correction possible, achievable with an implanted hydrophone. As a matter of fact, this drop is on the order of that induced by the presence of the wig and cap at 710 $\mathrm{kHz}$. CT-based corrections have been reported to restore $70 \%$ of the pressure at the focus at $660 \mathrm{kHz}$ [19] and $85 \%$ at $1 \mathrm{MHz}[30,31]$, as compared to hydrophone-based gold standard corrections. Based on the squared relationship between pressure and temperature, the aberration correction process yields a focal temperature rise that is $49 \%$ of that obtained with gold standard correction at $660 \mathrm{kHz}$, corresponding to a $51 \%$ drop in temperature elevation at the focus.

This is consistent with the fact that the human hair is expected to have minimal scattering effect because of its mean diameter. The human hair diameter is typically in the range between 30 and $110 \mu \mathrm{m}$ [32] and is thus negligible compared to the ultrasonic wavelength $(6.8 \mathrm{~mm}$ at $220 \mathrm{kHz}$ and $2.1 \mathrm{~mm}$ at $710 \mathrm{kHz}$ ).

Table 1 Slope of the linear least squares fit for each configuration

\begin{tabular}{lcc}
\hline & \multicolumn{2}{c}{ System $\left({ }^{\circ} \mathbf{C} / \mathbf{J}\right)$} \\
\cline { 2 - 3 } & $\mathbf{2 2 0} \mathbf{~ k H z}$ & $\mathbf{7 1 0 ~} \mathbf{~ H z}$ \\
\hline No wig and no cap & $1.1 \times 10^{-3}$ & $1.9 \times 10^{-3}$ \\
Cap alone & $0.88 \times 10^{-3}$ & $1.1 \times 10^{-3}$ \\
Cap and wig & $0.89 \times 10^{-3}$ & $0.91 \times 10^{-3}$ \\
\hline
\end{tabular}

Raymond and Hynynen reported similar results on acoustic transmission through homemade hair-mat phantoms made by placing aligned human hairs lengthwise between two acrylic supports [30], with a hair density varying from 294 to 521 hairs $/ \mathrm{cm}$. Within the range of frequencies studied here, they reported transmission loss lower than $20 \%$ with the hair phantom oriented perpendicular to beam propagation, whatever the hair density. Our results suggest that these findings remain valid in a more realistic geometry of the hair and scalp. One has to mention that the implementation of the natural hair on the commercial wig was enabled by the manufacturer with the use of a cap, the substructure to which the hair was attached (Figure 4). Such a cap is affecting the transmission of the beam, as can be seen in Table 1: 20\% relative drop in temperature elevation with the $220-\mathrm{kHz}$ array and $42 \%$ with the $710-\mathrm{kHz}$ array. Patients undergoing tcMRgFUS treatment are currently shaved and do not have such a cap. Most of the comments in the discussion use the cap as a reference to investigate the influence of the hair alone.

One can notice that four of the six wig-to-cap ratios are greater than $100 \%$ for the $220-\mathrm{kHz}$ array (Figure 6). The presence of the hair is nevertheless expected to decrease the transmission of ultrasound and thus decreases the temperature at the focus. As a matter of fact, all the corresponding measurements are close to $100 \%$ : the average absolute difference between the temperature elevations obtained with and without the wig for the $220-\mathrm{kHz}$ array is $0.2^{\circ} \mathrm{C}$, which is on the order of the precision of the MR temperature measurement.

The results show that the efficiency of the treatment is unlikely to be compromised by the presence of the hair. Nevertheless, even though only a fraction of the energy is lost when sonicating through the hair, part of this loss is likely to be absorbed by the hair and could potentially lead to skin burns. The corresponding temperature 


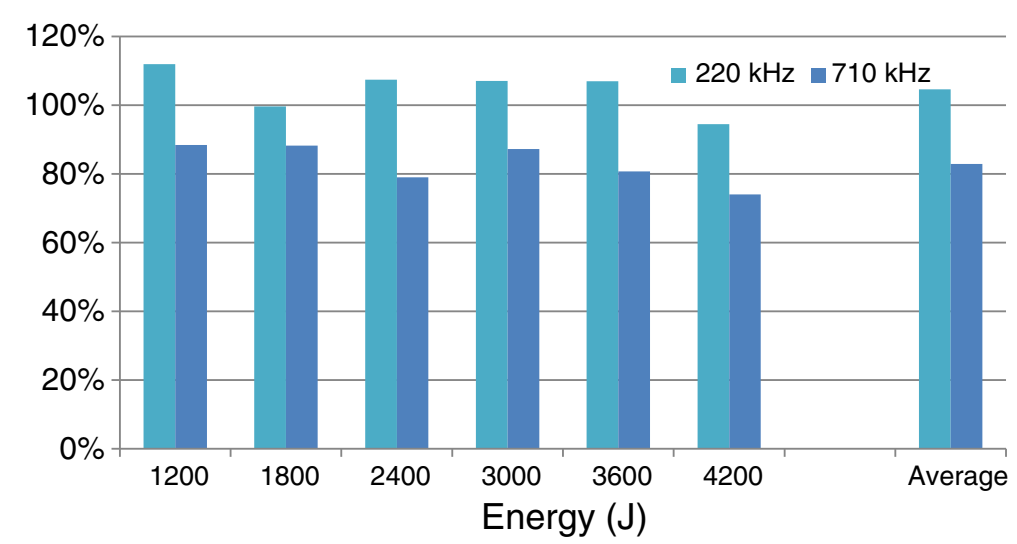

Figure 6 Wig to cap thermal rise ratio using 220 and $710 \mathrm{kHz}$.

elevation could not be measured here due to the presence of water only between the hair and the skull. In order to further investigate the temperature elevation in the hair and close to the hair, a more detailed model of a human head would have to be developed, including not only brain tissue-mimicking phantom, wig, and skull but also skin or embedding the hair in a gel. MR temperature monitoring during treatment is currently limited to one sagittal or coronal plane [23,24]. Current developments include full 3D MR thermometry of the whole brain volume [33]. Such methods could be extended in the future to monitor the temperature of the skin itself in the case of unshaved treatment.

One last difficulty for trans-hair treatment is that air bubbles can be trapped in the hair. Air bubbles are known to not only block ultrasound but also absorb ultrasonic energy. In this study, the wig was gently stirred by hand while submerged in the degassed water to remove trapped air bubbles. Such a hand stirring is possible to achieve in the current clinical setup, and circulation of degassed water is contributing to remove air bubbles once everything was in place.

\section{Conclusions}

Based on these very initial results and assuming that our full-scale model of cadaver skull and human hair wig setup is sufficiently similar to the clinical scenario, it should be possible to deliver trans-cranial focused ultrasound brain thermal ablation using either 220 - or $710-\mathrm{kHz}$ central frequency without shaving the hair. Further studies are needed to make sure that it does not result in significant thermal rise on the hair surface and on the skin.

\section{Competing interests}

Matthew DC Eames, John W Snell, and Jean-Francois Aubry declare that they have no competing interests. Arik Hananel and Neal F Kassell have shares in InSightec, the company which manufactures the ExAblate device.

\section{Authors' contributions}

MDCE, JWS, and AH performed the experiments. MDCE, JWS, AH, and J-FA conducted the data analysis and participated in writing the paper. NFK directed and supported the research. All authors read and approved the final manuscript.

\section{Author details}

${ }^{1}$ Focused Ultrasound Foundation, Charlottesville, VA 22903, USA. 2Department of Radiation Oncology, University of Virginia, Charlottesville, VA 22908, USA. ${ }^{3}$ Department of Neurosurgery, University of Virginia, Charlottesville, VA 22908, USA. Institut Langevin Ondes et Images, ESPCI ParisTech, CNRS UMR 7587, Inserm U979, Paris 75238, France.

Received: 26 June 2013 Accepted: 13 November 2013

Published: 2 January 2014

\section{References}

1. Crouzet S, Murat FJ, Pasticier G, Cassier P, Chapelon JY, Gelet A. High intensity focused ultrasound (HIFU) for prostate cancer: current clinical status, outcomes and future perspectives. Int J Hyperthermia. 2010; 26(8):796-803. doi:10.3109/02656736.2010.498803.

2. Elias WJ, Huss D, Voss T, Loomba J, Khaled M, Zadicario E, Frysinger RC, Sperling SA, Wylie S, Monteith SJ, Druzgal J, Shah BB, Harrison M, Wintermark M. A pilot study of focused ultrasound thalamotomy for essential tremor. N Engl J Med. 2013; 369(7):640-8. doi:10.1056/NEJMoa1300962.

3. Illing RO, Kennedy JE, Wu F, ter Haar GR, Protheroe AS, Friend PJ, Gleeson FV, Cranston DW, Phillips RR, Middleton MR. The safety and feasibility of extracorporeal high-intensity focused ultrasound (HIFU) for the treatment of liver and kidney tumours in a Western population. Brit J Cancer. 2005; 93(8):890-5. doi:10.1038/sj.bjc.6602803.

4. Wu F, Wang ZB, Chen WZ, Zhu H, Bai J, Zou JZ, Li KQ, Jin CB, Xie FL, Su HB. Extracorporeal high intensity focused ultrasound ablation in the treatment of patients with large hepatocellular carcinoma. Ann Surg Oncol. 2004; 11(12):1061-9. doi:10.1245/ASO.2004.02.026.

5. Wu F, Wang ZB, Chen WZ, Zou JZ, Bai J, Zhu H, Li KQ, Jin CB, Xie FL, Su HB. Advanced hepatocellular carcinoma: treatment with high-intensity focused ultrasound ablation combined with transcatheter arterial embolization. Radiology. 2005; 235(2):659-67. doi:10.1148/radiol.2352030916.

6. Wu F, Wang ZB, Zhu H, Chen WZ, Zou JZ, Bai J, Li KQ, Jin CB, Xie FL, Su HB. Extracorporeal high intensity focused ultrasound treatment for patients with breast cancer. Breast Cancer Res Treat. 2005; 92(1):51-60. doi:10.1007/s10549-004-5778-7.

7. Schmitz AC, Gianfelice D, Daniel BL, Mali WP, van den Bosch MA. Image-guided focused ultrasound ablation of breast cancer: current status, challenges, and future directions. Eur Radiol. 2008; 18(7):1431-41. doi:10.1007/s00330-008-0906-0.

8. Hesley GK, Gorny KR, Henrichsen TL, Woodrum DA, Brown DL. A clinical review of focused ultrasound ablation with magnetic resonance guidance: an option for treating uterine fibroids. Ultrasound Q. 2008 . 24(2):131-9. doi:10.1097/RUQ.0b013e31817c5e0c. 
9. Stewart EA, Rabinovici J, Tempany CM, Inbar Y, Regan L, Gostout B, Hesley G, Kim HS, Hengst S, Gedroyc WM. Clinical outcomes of focused ultrasound surgery for the treatment of uterine fibroids. Fertil Steril. 2006; 85(1):22-9. S0015-0282(05)03655-1.

10. Mikami K, Murakami T, Okada A, Osuga K, Tomoda K, Nakamura H. Magnetic resonance imaging-guided focused ultrasound ablation of uterine fibroids: early clinical experience. Radiat Med. 2008; 26(4):198-205. doi:10.1007/s11604-007-0215-6.

11. Bradley WG Jr. MR-guided focused ultrasound: a potentially disruptive technology. J Am Coll Radiol. 2009; 6(7):510-3. S1546-1440(09)00005-2.

12. Cline HE, Schenck JF, Hynynen K, Watkins RD, Souza SP, Jolesz FA. MR-guided focused ultrasound surgery. J Comput Assist Tomogr. 1992; 16(6):956-65.

13. Wu F, Wang ZB, Chen WZ, Zou JZ, Bai J, Zhu H, Li KQ, Xie FL, Jin CB, Su HB, Gao GW. Extracorporeal focused ultrasound surgery for treatment of human solid carcinomas: early Chinese clinical experience. Ultrasound Med Biol. 2004; 30(2):245-60. doi:10.1016/j.ultrasmedbio.2003.10.010.

14. Chaussy C, Thuroff S, Rebillard X, Gelet A. Technology insight: high-intensity focused ultrasound for urologic cancers. Nat Clin Pract Urol. 2005; 2(4):191-8. ncpuro0150.

15. Lynn JG, Putnam TJ. Histology of cerebral lesions produced by focused ultrasound. Am J Pathol. 1944; 20(3):637-49.

16. Lindstrom PA. Prefrontal ultrasonic irradiation-a substitute for lobotomy. AMA Arch Neurol Psychiatry. 1954; 72(4):399-425.

17. Fry W, Mosberg W, Barnard J, Fry F. Production of focal destructive lesions in the central nervous system with ultrasound. J Neurosurg. 1954; 11:471-8.

18. Fry FJ. Transkull transmission of an intense focused ultrasonic beam. Ultrasound Med Biol. 1977; 3(2-3):179-84.

19. Fry FJ, Barger JE. Acoustical properties of the human skull. J Acoust Soc Am. 1978; 63(5):1576-90

20. Clement $\mathrm{G}$, Hynynen K. A non-invasive method for focusing ultrasound through the human skull. Physics Med Biol. 2002; 47:1219-36.

21. Aubry JF, Tanter M, Pernot $M$, Thomas JL, Fink M. Experimental demonstration of noninvasive transskull adaptive focusing based on prior computed tomography scans. J Acoust Soc Am. 2003; 113(1):84-93.

22. Marsac L, Chauvet D, Larrat B, Pernot M, Robert B, Fink M, Boch AL, Aubry JF, Tanter M. MR-guided adaptive focusing of therapeutic ultrasound beams in the human head. Med Physics. 2012; 39:1141.

23. Monteith S, Sheehan J, Medel R, Wintermark M, Eames M, Snell J, Kassell NF, Elias WJ. Potential intracranial applications of magnetic resonance-guided focused ultrasound surgery: a review. J Neurosurg. 2013; 118(2):215-21.

24. Martin E, Jeanmonod D, Morel A, Zadicario E, Werner B. High-intensity focused ultrasound for noninvasive functional neurosurgery. Ann Neurol. 2009; 66(6):858-61. doi:10.1002/ana.21801.

25. Hynynen K, McDannold N, Vykhodtseva N, Jolesz FA. Non-invasive opening of BBB by focused ultrasound. Acta Neurochir Suppl. 2003; 86:555-8.

26. Choi JJ, Pernot M, Small SA, Konofagou EE. Noninvasive, transcranial and localized opening of the blood-brain barrier using focused ultrasound in mice. Ultrasound Med Biol. 2007; 33(1):95-104. S0301-5629(06)01746-7.

27. Liu HL, Wai YY, Chen WS, Chen JC, Hsu PH, Wu XY, Huang WC, Yen TC, Wang JJ. Hemorrhage detection during focused-ultrasound induced blood-brain-barrier opening by using susceptibility-weighted magnetic resonance imaging. Ultrasound Med Biol. 2008; 34(4):598-606. S0301-5629 (08)00016-1.

28. Culp WC, Porter TR, Lowery J, Xie F, Roberson PK, Marky L. Intracranial clot lysis with intravenous microbubbles and transcranial ultrasound in swine. Stroke. 2004; 35(10):2407-11. doi:10.1161/01.str.0000140890.86779.79.

29. Alexandrov AV, Molina CA, Grotta JC, Garami Z, Ford SR, Alvarez-Sabin J, Montaner J, Saqqur M, Demchuk AM, Moyé LA, Hill MD, Wojner AW CLOTBUST Investigators. Ultrasound-enhanced systemic thrombolysis for acute ischemic stroke. N Engl J Med. 2004; 351(21):2170-8. 351/21/2170.

30. Raymond SB, Hynynen K. Acoustic transmission losses and field alterations due to human scalp hair. IEEE T Ultrason Ferr. 2005; 52(8):1415-9. doi:10.1109/Tuffc.2005.1509801.

31. Wu T, Kendell KR, Felmlee JP, Lewis BD, Ehman RL. Reliability of water proton chemical shift temperature calibration for focused ultrasound ablation therapy. Med Physics. 2000; 27(1):221-4.

32. de Lacharrière ODCMC, Deloche C, Misciali C, Piraccini BM, Vincenzi C, Bastien P, Tardy I, Bernard BA, Tosti A. Hair diameter diversity: a clinical sign reflecting the follicle miniaturization. Arch Dermatol. 2001; 137(5):641-6. 10-1001/pubs.Arch Dermatol.-ISSN-0003-987x-137-5-dob10023.

33. Todd N, Vyas U, de Bever J, Payne A, Parker DL. Reconstruction of fully three-dimensional high spatial and temporal resolution MR temperature maps for retrospective applications. Magnetic Resonance Med. 2012; 67(3):724-30.

doi:10.1186/2050-5736-1-24

Cite this article as: Eames et al.: Trans-cranial focused ultrasound without hair shaving: feasibility study in an ex vivo cadaver model. Journal of Therapeutic Ultrasound 2013 1:24.

\section{Submit your next manuscript to BioMed Central and take full advantage of:}

- Convenient online submission

- Thorough peer review

- No space constraints or color figure charges

- Immediate publication on acceptance

- Inclusion in PubMed, CAS, Scopus and Google Scholar

- Research which is freely available for redistribution

Submit your manuscript at www.biomedcentral.com/submit
C BioMed Central 